\title{
A statistical study of BRIs (SMCs), isolated substorms, and individual sawtooth injections
}

\author{
A. D. DeJong, ${ }^{1,2}$ A. J. Ridley, ${ }^{2}$ X. Cai, ${ }^{3}$ and C. R. Clauer ${ }^{3}$ \\ Received 31 October 2008; revised 7 May 2009; accepted 29 May 2009; published 27 August 2009.
}

[1] There are many similarities and differences in the solar wind drivers during three of the main modes of convection in the magnetosphere (isolated substorms, global sawtooth oscillations, and steady magnetospheric convection (SMC) events, which we term here balanced reconnection intervals (BRI)). Thus, this investigation utilizes statistical analysis to compare the solar wind and interplanetary magnetic field (IMF) drivers and their steadiness (standard deviation divided by the mean) during these three different event types. By including the steadiness of the drivers, the importance of magnitude, sign, and stability of the drivers for the different modes can be investigated. A series of histograms with each mode plotted over top of 6 years of background is used to measure the deviation of the mode drivers from the nominal data, and also allows for a comparison between each event type. We found that the magnitude and direction of $\mathrm{B}_{z}$ are the dominate driver for substorms, while BRIs and sawteeth require both magnitude and steadiness of certain drivers to occur. Both BRIs and sawteeth show similar steadiness in their drivers, while the magnitude of the drivers is much stronger for the sawtooth oscillations. Also included in this study are the substorms that initiate BRIs. The solar wind and IMF drivers for the initiating substorms are similar to drivers for BRIs; thus initiating substorms of BRIs are different from isolated substorms and may play a role in preconditioning the magnetosphere for BRIs.

Citation: DeJong, A. D., A. J. Ridley, X. Cai, and C. R. Clauer (2009), A statistical study of BRIs (SMCs), isolated substorms, and individual sawtooth injections, J. Geophys. Res., 114, A08215, doi:10.1029/2008JA013870.

\section{Introduction}

[2] When the interplanetary magnetic field (IMF) is oriented such that it is antiparallel to Earth's magnetic field, plasma and energy from the solar wind can enter the magnetosphere. The magnetosphere can react to the plasma and energy in different ways. It can store (load) energy in the tail lobes and then release the energy (unload) into the inner magnetosphere and ionosphere. If this occurs locally and is an isolated event it is considered an isolated substorm [Russell and McPherron, 1973; Hones et al., 1984]. If this occurs globally and quasiperiodically then it is termed a global sawtooth oscillation, each unloading in the series is an individual sawtooth injection [Reeves et al., 2002; Henderson, 2004]. If the energy is not stored and released, but rather continuously diverted, then convection is quasisteady, the dayside and nightside reconnection rates are balanced, and the magnetosphere has achieved a balanced reconnection interval (BRI), sometimes described as a

\footnotetext{
${ }^{1}$ Southwest Research Institute, San Antonio, Texas, USA.

${ }^{2}$ Department of Atmospheric, Oceanic, and Space Sciences, University of Michigan, Ann Arbor, Michigan, USA.

${ }^{3}$ Bradley Department of Electrical and Computer Engineering, Virginia Polytechnic Institute and State University, Blacksburg, Virginia, USA.

Copyright 2009 by the American Geophysical Union. 0148-0227/09/2008JA013870
}

steady magnetospheric convection (SMC) mode [DeJong et al., 2008; Sergeev et al., 1996].

[3] These three different modes possess similarities and differences in magnetospheric configuration and solar wind drivers. Sawtooth injections in many ways resemble large isolated substorms. Cai et al. [2006a, 2006b] statistically compared the differences between sawtooth injections and isolated substorms in terms of the ionospheric potential patterns and magnetic dipolarization. They and others have found that the sawtooth injections are larger and more global than isolated substorms [Henderson et al., 2006a, 2006b; Clauer et al., 2006]. DeJong et al. [2007] found that the open magnetic flux in the polar cap $\left(\mathrm{F}_{P C}\right)$ during the expansion phase of both sawteeth and substorms decreases by $30 \%$, yet the total $\mathrm{F}_{P C}$ for the individual sawtooth injections is $50 \%$ larger than for isolated substorms. Thus, many believe global sawtooth oscillations to be periodic substorms [Huang et al., 2003, 2005].

[4] There are also many ways both isolated substorm and sawtooth oscillations can be similar to BRIs. DeJong et al. [2007] found that isolated substorms have an auroral intensity and total polar cap open magnetic flux $\left(\mathrm{F}_{P C}\right)$ similar to that of SMCs (BRIs). While sawtooth oscillations tend to occur when the IMF $B_{z}$ is steady and on average approximately $-8 \mathrm{nT}$, SMCs (BRIs) occur when it is steady and on average $-3 \mathrm{nT}$ [O'Brien et al., 2002; McPherron et al., 2008]. Also, double ovals in the auroral have been observed during both BRIs and sawtooth oscillations 


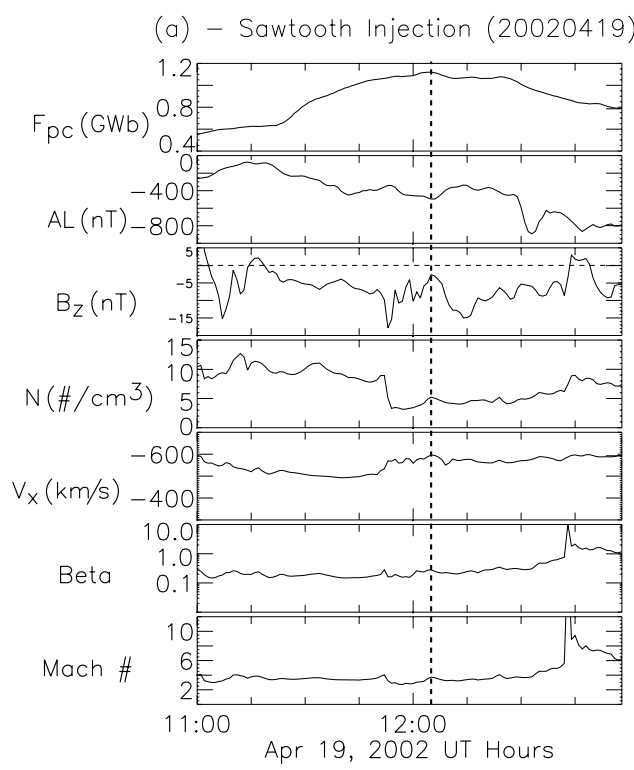

(b) $-\mathrm{BRI} / \mathrm{SMC}(20001026)$

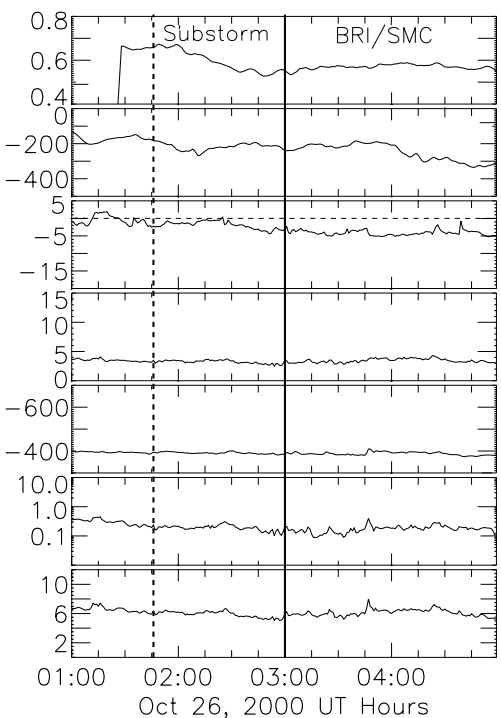

(c) - Isolated Substorm (19970912)

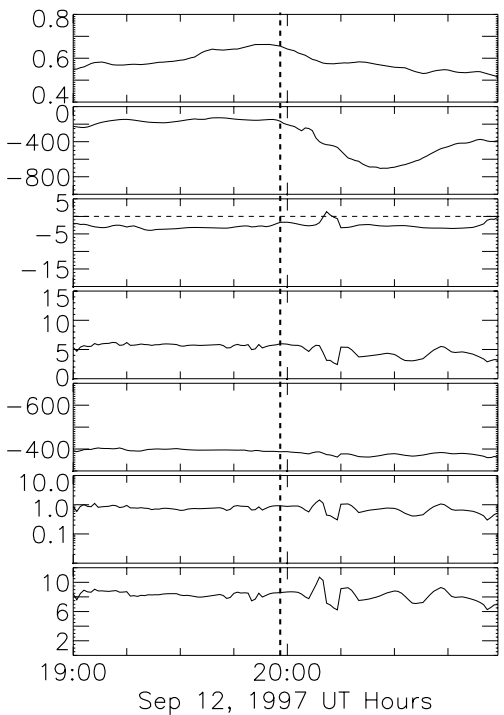

Figure 1. Stack plots of the ionospheric and solar wind parameters for each convection mode. (a) The sawtooth injection on 19 April 2002 with an onset at 1205 UT shown by the dotted line. (b) The BRI/ SMC on 26 October 2000. The onset time of the BRI/SMC is at 0300 UT shown by the solid line. Also plotted in the $2 \mathrm{~h}$ preceding the BRI/SMC the dotted line indicates the onset of the expansion of the substorm that initiates the BRI/SMC. (c) The isolated substorm that occurs on 12 September 1997 with an onset time of $1158 \mathrm{UT}$.

[Henderson et al., 2006a]. Pulkkinen et al. [2007b] found that when the IMF $B_{z}$ remains steady and the solar wind speed is increased the magnetosphere becomes more dynamic, thus it is expected that both a steady IMF $\mathrm{B}_{z}$ and large solar wind speed may create a global sawtooth oscillation.

[5] This study expands upon previous work by investigating both the magnitude and the steadiness of the solar wind and IMF drivers. By looking at both the drivers and the changes in the drivers, we aim to identify specific components of the solar wind or IMF that may play a significant role in determining the type of convection mode that develops in the magnetosphere. This paper presents a detailed, comprehensive statistical analysis that investigates the differences and similarities in the solar wind and IMF drivers for individual sawtooth injections, isolated substorms, and BRIs. While others have previously investigated most of the parameters studied here, none investigate a steadiness parameter of the drivers. Additionally, most of the previous research concentrates on only one event type or one parameter [McPherron et al., 1986; O'Brien et al., 2002; Pulkkinen et al., 2007b; Borovsky and Denton, 2006]. This is also the first known investigation that treats the substorms that initiate BRIs as a separate event type. This separate treatment allows for a better comparison of the drivers of BRI initiating substorms to the BRIs that follow them and to the isolated substorms. This separation of BRIs and their initiating substorm will lead to a better understanding of the preconditioning of the magnetosphere for BRIs.

\section{Data and Methodology}

[6] This analysis utilizes 210 individual sawtooth injections, 212 isolated substorms and 51 balanced reconnection intervals (BRIs) events. The data for the isolated substorms and the sawtooth injections are taken from one hour before to one after the onset of the expansion phase or injection. The onset time for the substorm expansions is determined using midlatitude magnetometer data [Cai et al., 2006a]. The injection time for the individual sawteeth is determined by LANL SOPA proton data. For more information on how these are determined the reader is referred to Cai et al. [2006a]. All BRI time intervals are determined using the methodology set forth by DeJong and Clauer [2005] and DeJong et al. [2007] in which a steady open polar cap magnetic flux is used to determine BRIs. The data for the BRI events are for the entire time interval of the event, ranging from 3 to $15 \mathrm{~h}$. Also plotted for the BRIs are the $2 \mathrm{~h}$ preceding the event. Since 50 out of 51 of the BRIs have an initiating substorm during this time we compare this set of initiating substorms to the set of isolated substorms. All data are one minute time resolution (averaged), the total amount of data used for the BRIs is $327 \mathrm{~h}, 102 \mathrm{~h}$ for the times preceding the BRIs, and the sawteeth and substorm data are 420 and $424 \mathrm{~h}$, respectively. All of the events occur between January 1997 and December 2002. The average conditions are determined from all of the data during this 6 year time interval.

[7] The IMF and solar wind data are from ACE. When ACE data are not available, Wind data are used. All parameters have been propagated to Earth using the Weimer et al. [2002], Weimer et al. [2003], and Weimer [2004] pseudo-minimum variance technique. The propagation is accurate to approximately $6 \mathrm{~min}$, thus onsets and triggers may not occur at the exact same time.

[8] Figure 1 shows an example for each convection of the three modes, of some of the data used in this study. The stack plot in Figure 1a is an example of a sawtooth 
injection. The data are plotted approximately $1 \mathrm{~h}$ before the injection time (12:05 UT) to $1 \mathrm{~h}$ after the injection. The dotted vertical line represents the onset time of the sawtooth injection. While the injection onset is not seen very well in the AL (Figure 1a, second panel) data it does correlate with peak of the open magnetic flux in the polar cap $\left(\mathrm{F}_{p c}\right)$ (Figure 1a, first panel). The IMF $\mathrm{B}_{z}$ (Figure 1a, third panel) for the sawtooth injection is negative for most of the $2 \mathrm{~h}$ interval but it is not very steady as it fluctuates between $2 \mathrm{nT}$ and $-18 \mathrm{nT}$ with an average of $-5.9 \mathrm{nT}$. The solar wind density (Figure 1a, fourth panel) drops from 8 to 3 about 15 min before the onset of the injection, while the solar wind velocity (Figure 1a, fifth panel) remains high $(555 \mathrm{~km} / \mathrm{s})$ and steady during this period. Both solar wind Beta (Figure 1a, sixth panel) and Alfvenic (Figure 1a, seventh panel) Mach number are steady and low until 12:40 UT.

[9] The stack plot in Figure 1b is an example of a BRI. The solid vertical line represents the onset of the BRI (03:00 UT), when $\mathrm{F}_{p c}$ become steady. Two hours of preceding data are also plotted. The dotted vertical line indicates the onset of the expansion phase (01:47 UT) of the initiating substorm. This onset correlates well with the peak in $\mathrm{F}_{p c}$ (Figure $1 \mathrm{~b}$, first panel) and a decrease in AL (Figure 1b, second panel). During the entire $4 \mathrm{~h}$ interval (before and after the onset of the BRI) the solar wind/IMF parameters (Figure 1b, third through seventh panels) are steady and moderate. There appears to be no solar wind trigger for the substorm at 0147 UT that precedes the BRI.

[10] The stack plot in Figure 1c represents an example of an isolated substorm. The onset, shown by the vertical dotted line, is at 19:58 UT. The onset overlaps nicely with the peak in $\mathrm{F}_{p c}$ (Figure 1c, first panel), and the initiation of a drop in AL (Figure 1c, second panel). Like the substorm that initiated the BRI (Figure 1b) there is no external trigger for this isolated substorm, all solar wind and IMF parameters (Figure 1c, third through seventh panels) are steady and nominal during this period.

\section{Raw Values of Data}

\subsection{Histograms}

[11] The first part of this study is a statistical analysis of solar wind and IMF data that occur during the time frame around onsets of the expansion phase of isolated substorms, around the injection time of individual sawteeth, the $2 \mathrm{~h}$ preceding BRIs, the entire interval of the BRIs, and during the 6 years in which these events occur.

[12] All plots shown in this part of the study are histograms. In Figures 2-4 the data are of the same solar wind parameter going from left to right: sawtooth injections, BRIs, the $2 \mathrm{~h}$ before the BRI, and isolated substorms. The gray dotted histogram in each plot is 6 years of data (19972002); thus it is the same in each convection mode histogram. Plotting the background data allows for a comparison of each convection mode to "average" conditions. At the top of each histogram are arrows that indicate the mean $(\mathrm{M})$ and the peak $(\mathrm{P})$ for the convection mode in black and the 6 years of data in gray. The peak represents the most common data value and the mean is the average of the data. Please note that one extreme data point can effect the mean, but in general using one minute data for long periods of time, as we do here, one or two extremes should have little effect. If the data are spread evenly around a peak then the mean and the peak will be the same, for example, the IMF $B_{z}$ for the background data. The mean, peak, and standard deviation (STD) for each histogram are listed in Table 1.

[13] Also on each plot is the p value calculated using the chi-square test [Chernoff and Lehmann, 1954]. The chisquare test compares an expected probability distribution (the background data), to an observed outcome distribution (the convection mode). The $\mathrm{p}$ value represents the probability that the observed distribution (convection mode) is a random sample of the expected distribution (background data). Thus, if the $p$ value is close to 1 , then the observed data have a distribution that is similar to the expected distribution. So, for our purposes here, if the $\chi^{2} \mathrm{p}$ value, printed in the top right of each histogram, is small, less than 0.05 , the data for that convection mode are statistically different from the background data.

[14] Figures $2 \mathrm{a}-2 \mathrm{~d}$ (first panels) are histograms of the IMF $B_{z}$ for all four convection modes. The 6 years of background data (dotted lines) in Figures $2 \mathrm{a}-2 \mathrm{~d}$ (first panels) are distributed around $0 \mathrm{nT}$ with a standard deviation of $4.0 \mathrm{nT}$. All four of the convection modes are shifted to the negative side of the plot as expected since a negative IMF $B_{z}$ is more geoeffective than a positive IMF $B_{z}$. The individual sawtooth injections (Figure $2 \mathrm{a}$, first panel) have the largest magnitude of negative $\mathrm{B}_{z}$ with mean of $-7.8 \mathrm{nT}$, they also have the largest spread in the data, indicating that they may occur over a wide range of negative $B_{z}$. The histograms of the IMF $B_{z}$ for the BRIs (Figure $2 b$, first panel), the $2 \mathrm{~h}$ before the BRIs (Figure 2c, first panel) and substorms (Figure 2d, first panel) have a similar shape and peak, with the BRIs and the $2 \mathrm{~h}$ preceding them having slightly larger magnitude in IMF $\mathrm{B}_{z}$ than the isolated substorms.

[15] Figures $2 \mathrm{a}-2 \mathrm{~d}$ (second panels) show the data for solar wind temperature during these event types. The solar wind temperature has been derived from the thermal velocity of the solar wind using $T=m_{i} V_{\text {therm }} / 2 k$ where $k$ is the Boltzman constant. The background temperature (Figures $2 \mathrm{a}-2 \mathrm{~d}$, second panels) during the 6 years over which the events occur has a peak at $0.4 \times 10^{5} \mathrm{~K}$ and a mean of $1.5 \times 10^{5} \mathrm{~K}$. The difference between these two numbers is due to the long tail that decays at the higher temperatures. The sawteeth (Figure 2a, second panel) have a strong peak at $0.10 \times 10^{5} \mathrm{~K}$ but also have a long thick tail that extends past $5 \times 10^{5} \mathrm{~K}$. This indicates that while most sawteeth occur when the solar wind temperature is low $\left(<0.5 \times 10^{5} \mathrm{~K}\right)$ they can also occur over a very large range of temperatures. The BRIs (Figure $2 b$, second panel) and the $2 \mathrm{~h}$ before the them (Figure 2c, second panel) both have a double peak in the temperatures and are very similar in their mean, peak and standard deviation (see Table 1). They both also have very few data points above $2 \times 10^{5} \mathrm{~K}$; thus BRIs to not tend to occur when the temperature in the solar wind is high. The isolated substorm solar wind temperatures (Figure 2d, second panel) are similar to the background and shows no major deviation from the background data as indicated by the $\chi^{2} \mathrm{p}$ value of 0.88 .

[16] Solar wind density is plotted in Figures $2 \mathrm{a}-2 \mathrm{~d}$ (third panels). The density during the 6 years of background data (Figures $2 \mathrm{a}-2 \mathrm{~d}$, third panels) peaks at $4.1 \mathrm{~cm}^{-3}$ and has a mean of $7.2 \mathrm{~cm}^{-3}$. All four of the convection modes have density distributions thats are not significantly different from 
(a) - Sawteeth
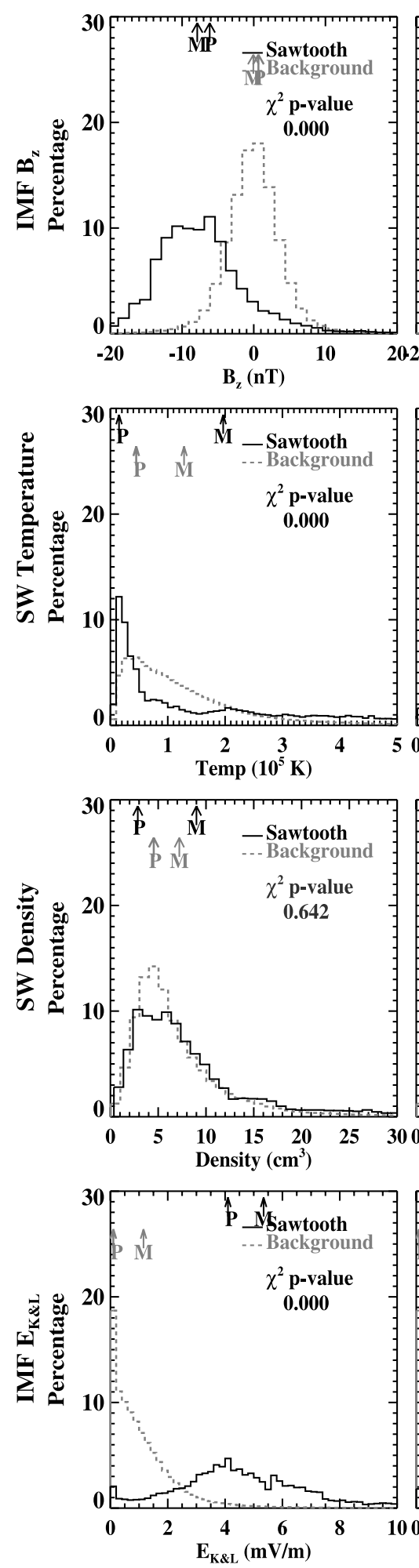

(b) - BRI/SMC

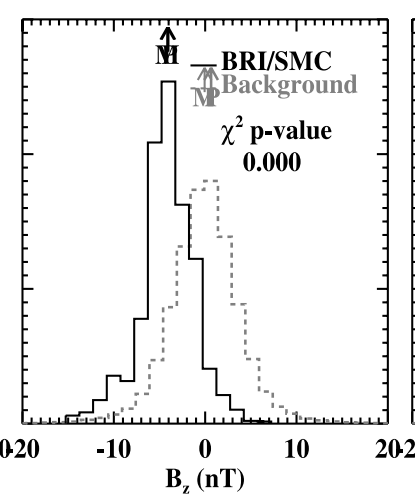

$\mathrm{B}_{z}(\mathrm{nT})$
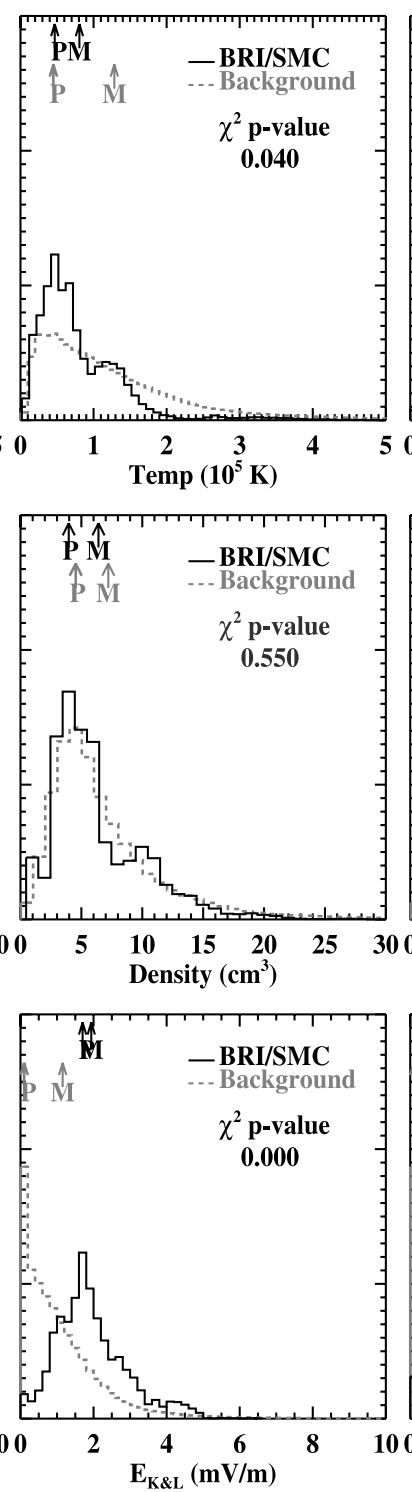

(c) - $2 \mathrm{~h}$ before BRI/SMC

(d) - Isolated Substorms
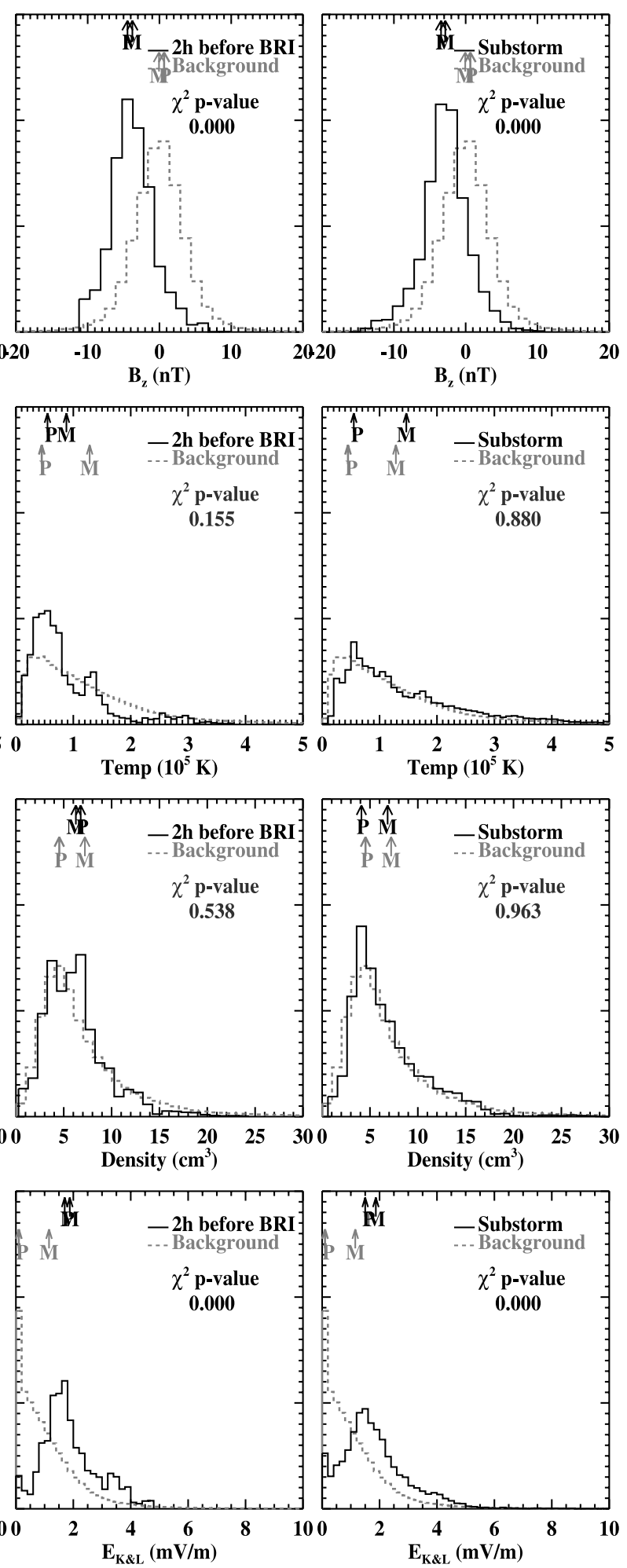

Figure 2. Histograms of the solar wind and IMF data for (a) individual sawtooth injections, (b) BRI/ $\mathrm{SMC}$, (c) the $2 \mathrm{~h}$ of data preceding the BRI/SMC, and (d) isolated substorms. From top to bottom, data for IMF $\mathrm{B}_{z}(\mathrm{nT})$, solar wind temperature $\left(10^{5} \mathrm{~K}\right)$, solar wind number density, $\rho\left(\mathrm{cm}^{-3}\right)$, and IMF $\mathrm{E}_{K \& L}$ are presented. The solid line on each histogram represents the event data (sawtooth, BRI/SMC, or substorm); the dotted gray line is a histogram of 6 years of background data over which the events occur (19972002). 
(a) - Sawteeth
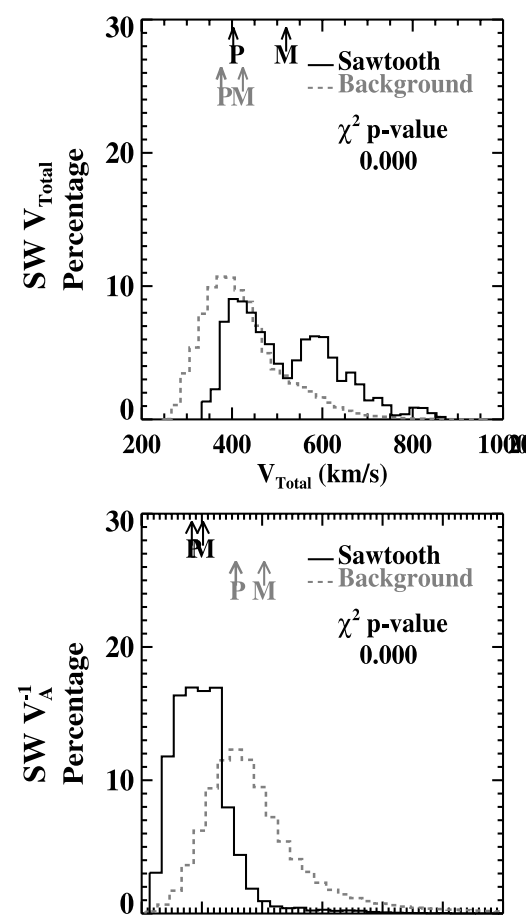

(b) - BRI/SMC
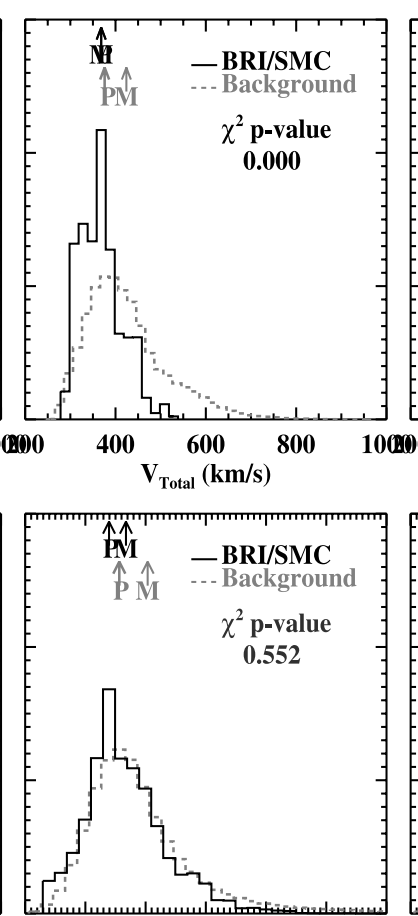

(c) - $2 \mathrm{~h}$ before BRI/SMC

(d) - Isolated Substorms
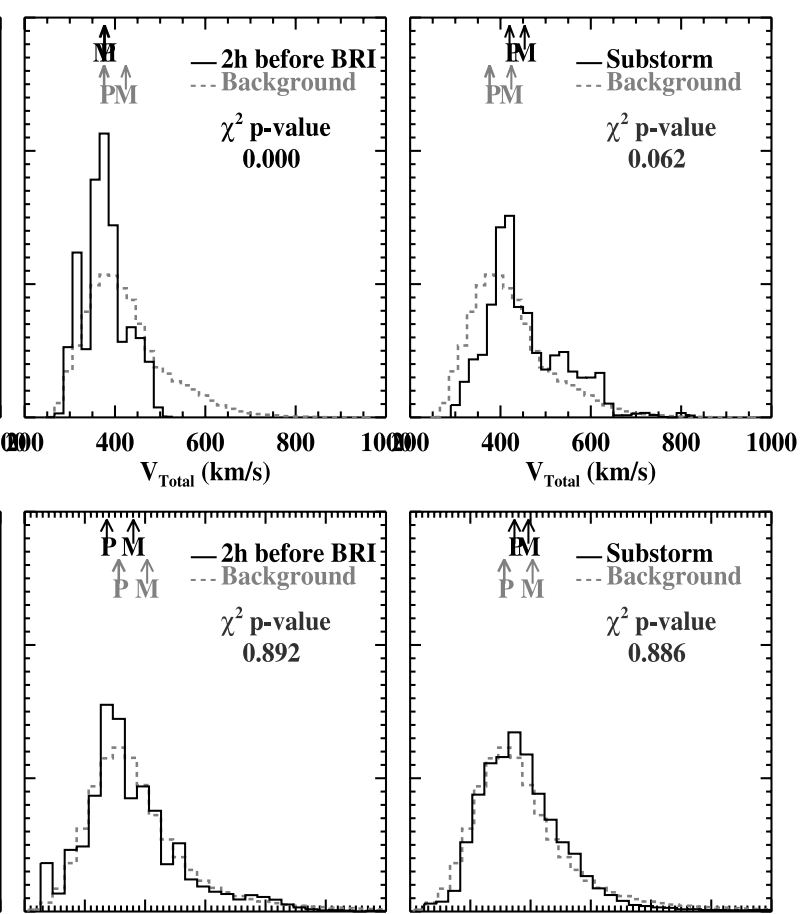

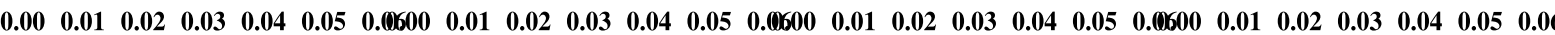
$\mathrm{V}_{\mathrm{A}}^{-1}(\mathrm{~s} / \mathrm{km})$ $\mathrm{V}_{\mathrm{A}}^{-1}(\mathrm{~s} / \mathrm{km})$

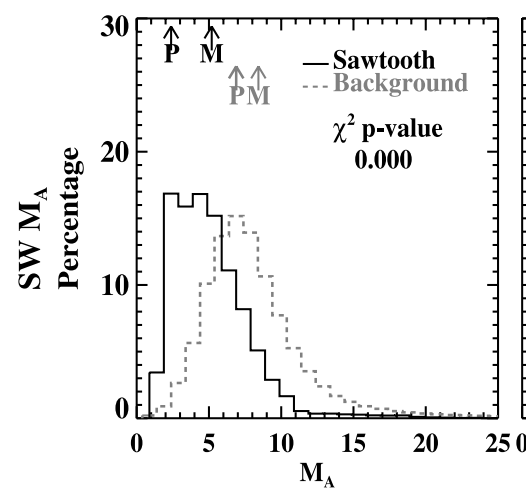

$\mathrm{V}_{\mathrm{A}}^{1}(\mathbf{s} / \mathbf{k m})$
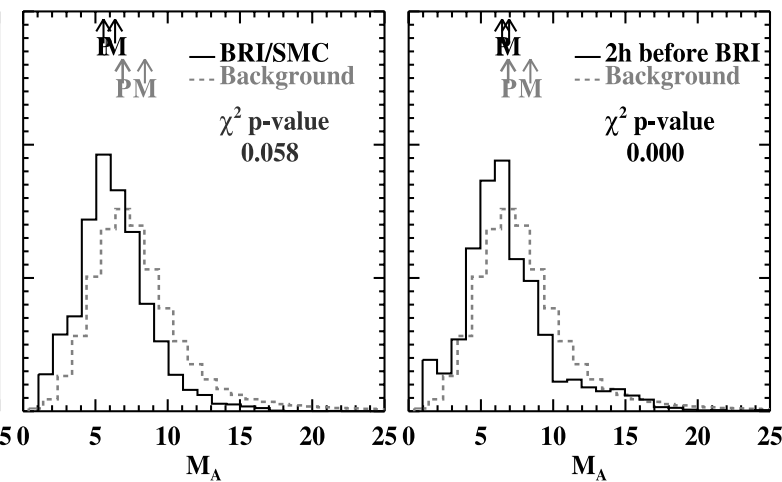

$\mathrm{V}_{\mathrm{A}}^{-1}(\mathrm{~s} / \mathrm{km})$
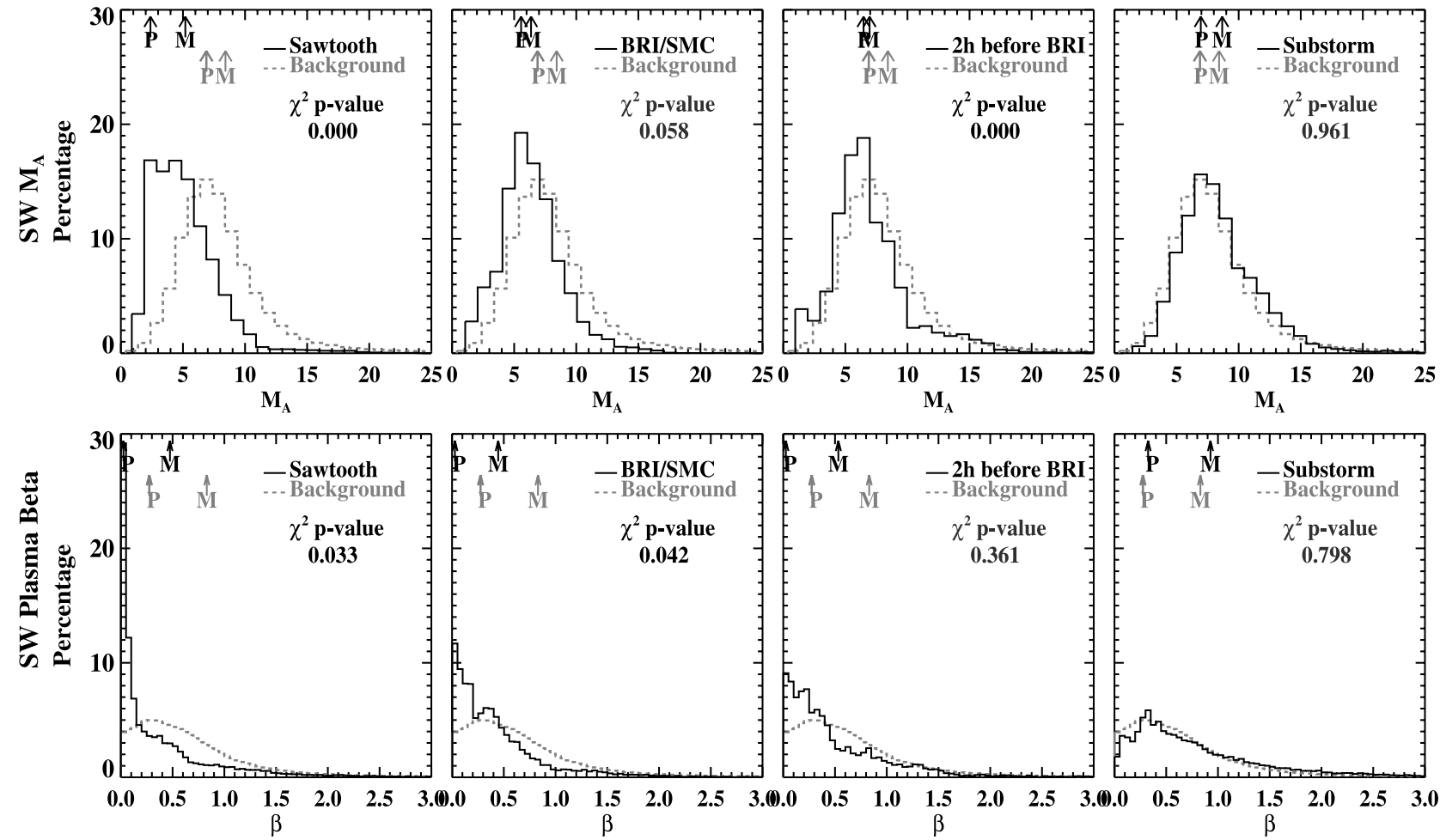

Figure 3. Histograms of the solar wind and IMF data for (a) individual sawtooth injections, (b) BRI/ $\mathrm{SMC}$, (c) the $2 \mathrm{~h}$ of data preceding the BRI/SMC, and (d) isolated substorms. From top to bottom, data for solar total velocity $(\mathrm{km} / \mathrm{s})$, the inverse of the solar wind Alfven velocity, solar wind Alfvenic Mach number, and solar wind plasma beta are presented. The solid line on each histogram represents the event data (sawtooth, BRI/SMC, or substorm); the dotted gray line is a histogram of 6 years of background data over which the events occur (1997-2002). 
(a) - Sawteeth

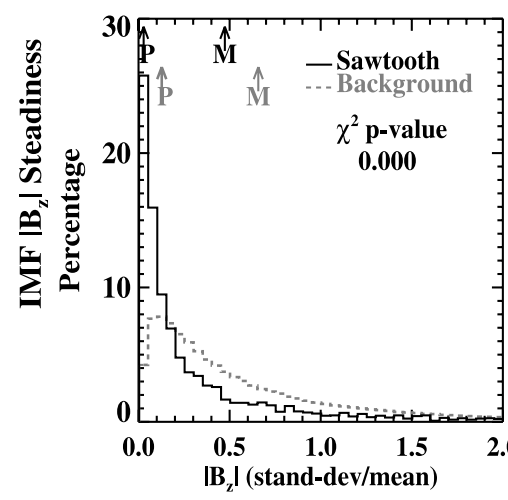

(b) - BRI/SMC

(c) - $2 \mathrm{~h}$ before BRI/SMC

(d) - Isolated Substorms
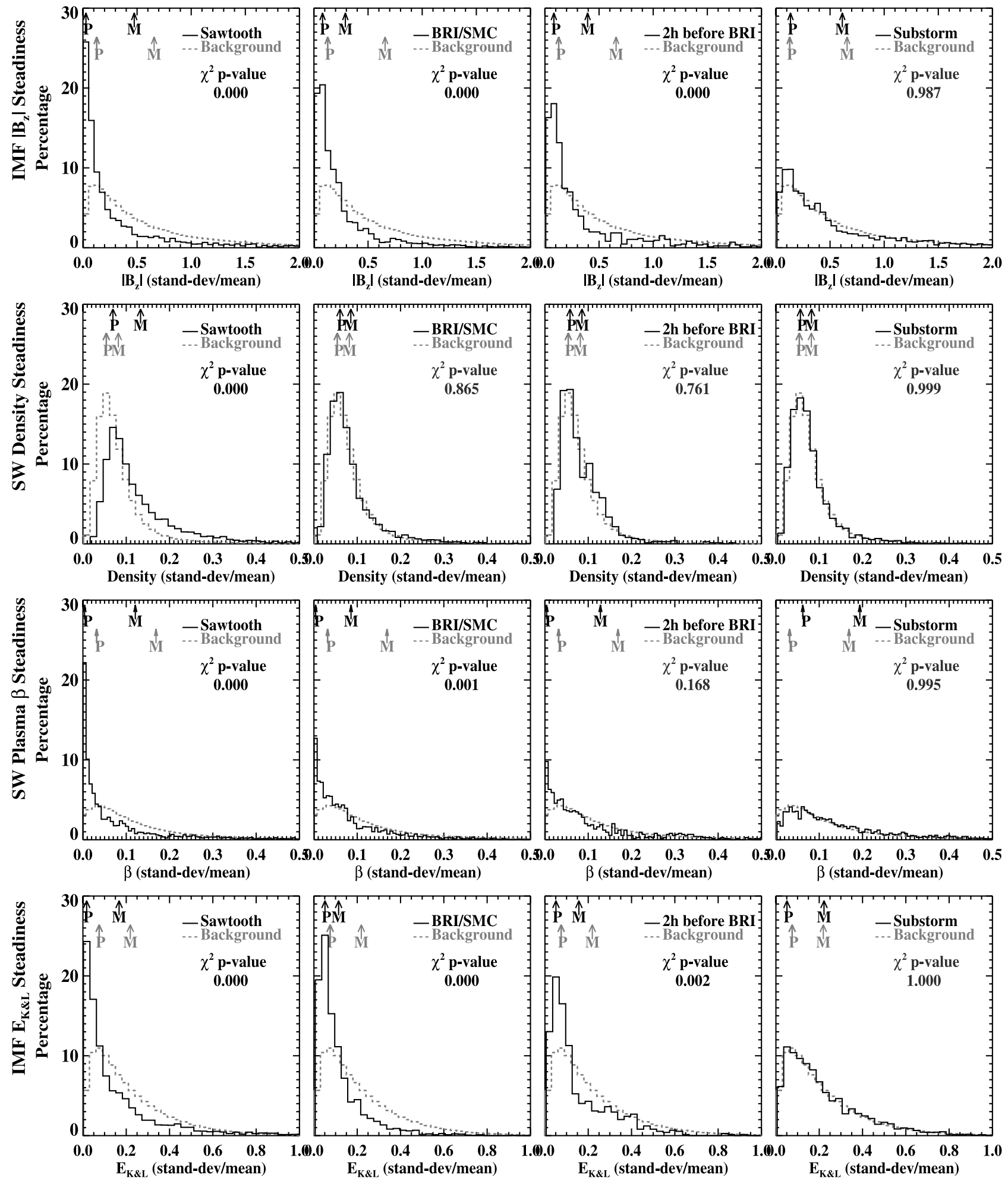

Figure 4. Histograms of the steadiness (standard deviation divided by the mean of a 30 min period) of solar wind and IMF parameters for (a) individual sawtooth injections, (b) BRI/SMC, (c) the $2 \mathrm{~h}$ of data preceding the BRI/SMC, and (d) isolated substorms. From top to bottom, data for the absolute value of the steadiness of IMF $\mathrm{B}_{z}$, the steadiness of the solar wind densities, the steadiness of the solar wind plasma beta, and the steadiness of IMF $\mathrm{E}_{K \& L}$ are presented. The solid line on each histogram represents the event data (sawtooth, BRI/SMC, or substorm); the dotted gray line is a histogram of 6 years of background data over which the events occur (1997-2002). 
Table 1. Peak, Mean, and Standard Deviation for the Histograms in Figures 2 and 3

\begin{tabular}{|c|c|c|c|c|c|c|c|c|c|c|c|c|c|c|c|}
\hline \multirow{2}{*}{$\begin{array}{c}\text { Solar Wind/IMF } \\
\text { Measurement }\end{array}$} & \multicolumn{3}{|c|}{ Sawtooth } & \multicolumn{3}{|c|}{$\mathrm{BRI} / \mathrm{SMC}$} & \multicolumn{3}{|c|}{$2 \mathrm{~h}$ Before BRI } & \multicolumn{3}{|c|}{ Substorm } & \multicolumn{3}{|c|}{ Background } \\
\hline & Mean & Peak & STD & Mean & Peak & STD & Mean & Peak & STD & Mean & Peak & STD & Mean & Peak & STD \\
\hline $\mathrm{IMF} \mathrm{B}_{z}(\mathrm{nT})$ & -7.8 & -6.9 & 7.1 & -4.2 & -4.7 & 3.0 & -3.77 & -5.2 & 3.07 & -2.8 & -4.2 & 3.4 & -0.06 & -0.10 & 4.04 \\
\hline Temp $\left(10^{5} \mathrm{~K}\right)$ & 1.96 & 0.10 & 2.11 & 0.81 & 0.42 & 0.62 & 0.88 & 0.50 & 0.67 & 1.47 & 0.50 & 1.10 & 1.21 & 0.40 & 1.08 \\
\hline Density $\left(\mathrm{cm}^{-3}\right)$ & 9.0 & 2.4 & 8.6 & 6.4 & 3.5 & 4.1 & 6.27 & 6.27 & 3.46 & 6.8 & 3.6 & 4.1 & 7.2 & 4.1 & 5.9 \\
\hline $\mathrm{E}_{K \& L}(\mathrm{mV} / \mathrm{m})$ & 5.34 & 4.00 & 3.57 & 1.94 & 1.60 & 0.98 & 1.87 & 1.60 & 0.97 & 1.87 & 1.40 & 1.32 & 1.15 & 0.0 & 1.31 \\
\hline $\mathrm{V}_{T}(\mathrm{~km} / \mathrm{s})$ & 519.8 & 392.8 & 112.5 & 368.3 & 358.4 & 46.4 & 377.7 & 366.0 & 47.8 & 453.6 & 410.0 & 86.8 & 424.1 & 366.0 & 89.3 \\
\hline $\mathrm{V}_{A}^{-1}\left(10^{-3} \mathrm{~s} / \mathrm{km}\right)$ & 10.2 & 7.3 & 6.0 & 16.7 & 12.9 & 7.0 & 18.1 & 12.6 & 8.7 & 19.6 & 16.3 & 11.3 & 20.3 & 14.6 & 15.0 \\
\hline $\mathrm{M}_{A}$ & 5.19 & 1.88 & 3.08 & 6.36 & 5.06 & 2.57 & 6.95 & 5.97 & 3.26 & 8.68 & 6.45 & 4.39 & 8.42 & 6.38 & 5.41 \\
\hline $\mathrm{SW} \beta$ & 0.47 & 0.0 & 2.82 & 0.45 & 0.0 & 0.53 & 0.53 & 0.00 & 0.65 & 0.93 & 0.32 & 1.78 & 0.83 & 0.25 & 4.97 \\
\hline
\end{tabular}

the background distribution according to the $\chi^{2} \mathrm{p}$ values. However, it is interesting to note that sawteeth densities (Figure 2a, third panel) have broad peak and thicker tail then the rest of the event types.

[17] The last solar wind parameter evaluated in Figure 2 is the Kan and Lee electric field $\left(\mathrm{E}_{K \& L}\right)$ where $E_{K \& L}=V_{x}$ $B_{z y} \sin ^{2}(\theta / 2)$ and $V_{x}$ is the solar wind velocity in the $\mathrm{x}$ direction, $B_{z y}$ is IMF in z-y plane and $\theta$ is the angle between $\mathrm{B}_{y}$ and $\mathrm{B}_{z}$ [Kan and Lee, 1979]. If it is assumed that $\mathrm{V}_{x}$ dominates the $\mathrm{V}_{T}$ and $\mathrm{B}_{z}$ dominates $\mathrm{B}_{z y}$ then $\mathrm{E}_{K \& L}$ becomes a combination of Figures $2 \mathrm{a}-2 \mathrm{~d}$ (first panels) and Figures $3 a-3 d$ (first panels). The large peak close to zero for the background data (Figures $2 \mathrm{a}-2 \mathrm{~d}$, fourth panels) can be attributed to times when the IMF $\mathrm{B}_{z}$ is positive. Since none of the four convection modes studied here are likely to occur when the IMF $B_{z}$ is positive it is difficult to compare the $\mathrm{E}_{K \& L}$ of each mode to the background data. Because $\mathrm{E}_{K \& L}$ is related to the IMF merging efficiency, it can be considered the geoeffective electric field. The $\mathrm{E}_{K \& L}$ has a large magnitude and spread during the sawtooth injections (Figure 2a, fourth panel), while the time preceding the BRIs (Figure 2c, second panel), the BRIs (Figure 2b, second panel), and substorms (Figure 2d, second panel) peak close together (1.60, 1.60 and 1.40, respectively) and have slightly different standard deviations of $0.98,0.97$ and 1.32; see Table 1.

[18] Figures $3 a-3 d$ (first panels) are histograms of the solar wind total velocity $\left(\mathrm{V}_{T}\right)$ drivers for each convection mode. The average solar wind velocity from the background distribution (Figures $3 \mathrm{a}-3 \mathrm{~d}$, first panels) is $424 \mathrm{~km} / \mathrm{s}$, while the peak occurs at $366 \mathrm{~km} / \mathrm{s}$. The sawtooth injections (Figure 3a, first panel) have a bimodal distribution with the first peak at approximately $400 \mathrm{~km} / \mathrm{s}$ and the second one at approximately $600 \mathrm{~km} / \mathrm{s}$. The substorm $\mathrm{V}_{T}$ (Figure $3 \mathrm{~d}$, first panel) also peaks at about $400 \mathrm{~km} / \mathrm{s}$ and has a large tail that reaches approximately $650 \mathrm{~km} / \mathrm{s}$, then abruptly cuts off. The BRI $V_{T}$ (Figure $2 \mathrm{~b}$, first panel) and the times before the BRI (Figure 3c, first panel) both peak close to the same velocity as the background data, but the peaks are much larger at $22 \%$ verses the $11 \%$ for the background. Also the $\mathrm{V}_{T}$ for the BRIs has a very small range relative to the background data and the data for the other convection modes: the solar wind speed rarely goes above $450 \mathrm{~km} / \mathrm{s}$ during a BRI; see Table 2 .

[19] The inverse of the Alfven velocity $\left(\mathrm{V}_{A}^{-1}\right.$ where $V_{A}=B /$ $\left.B /\left(4 \pi m_{i} n_{i}\right)^{1 / 2}\right)$ histograms are plotted in Figures $3 \mathrm{a}-3 \mathrm{~d}$ (second panels). The $\mathrm{V}_{A}^{-1}$ for the 6 years of background data (Figures $3 \mathrm{a}-3 \mathrm{~d}$, second panels) peaks at $0.015 \mathrm{~s} / \mathrm{km}$ and has a mean of $0.020 \mathrm{~s} / \mathrm{km}$. The $\mathrm{V}_{A}^{-1}$ during BRIs (Figure 2b, second panel), time preceding the BRIs (Figure $3 \mathrm{c}$, second panel) and isolated substorms (Figure 3d, second panel) is statistically comparable to the background data according to the $\chi^{2} \mathrm{p}$ values. The sawteeth (Figure $3 \mathrm{a}$, second panel) have a high $\mathrm{V}_{A}$, causing the $\mathrm{V}_{A}^{-1}$ to be low. The $\mathrm{V}_{A}^{-1}$ for the sawteeth injections also has a very tight range: there are few data points above $0.02 \mathrm{~s} / \mathrm{km}$.

[20] Figures $3 a-3 d$ (third panels) are histograms of the Alfvenic Mach number $\left(\mathrm{M}_{A}=\mathrm{V}_{T} / \mathrm{V}_{A}\right)$. Thus, it is a combination of Figures $3 a-3 d$ (first panels) and Figures $3 a-3 d$ (second panels). The background $\mathrm{M}_{A}$ (Figures $3 \mathrm{a}-3 \mathrm{~d}$, third panels) peaks at 6.4 and has a mean of 8.4. As discussed above, the sawteeth occur during large solar wind $\mathrm{V}_{T}$ (Figure 3a, first panel) and large $\mathrm{V}_{A}$ (Figure $3 \mathrm{a}$, second panel), yet the Alfvenic Mach (Figure 3a, third panel) number is low compared to the background data. This indicates that the $\mathrm{V}_{A}$ dominates the $\mathrm{M}_{A}$ during sawtooth injections. The BRIs (Figure 3b, third panel) and the $2 \mathrm{~h}$ before them (Figure 3c, third panel) also occur during lower Alfvenic Mach numbers than the background, but in this case the low solar wind $\mathrm{V}_{T}$ determines the Alfvenic Mach number. The isolated substorms (Figure 3d, third panel) tend to occur during nominal Alfvenic Mach number conditions as the $\chi^{2} \mathrm{p}$ value is 0.961 .

[21] Figures $3 a-3 d$ (fourth panels) are the histograms for the solar wind plasma Beta $(\beta)$, which is the ratio of plasma pressure to the magnetic pressure, $\beta=2 \mu_{o} n k T / B^{2}$. The $\beta$ is a combination of the solar wind density, temperature, and IMF $B_{T}$. During sawtooth injections, the solar wind $\beta$ (Figure $3 \mathrm{a}$, fourth panel) tends to be much less than the background data. The histogram for the sawtooth $\beta$ drops off quickly but has a long tail. This indicates that, while the $\beta$ in the solar wind is usually small during sawtooth injections, they can also occur when the solar wind $\beta$ is large, similar to the temperature. The solar wind $\beta$ for the BRIs (Figure 3b, fourth panel) and their preceding $2 \mathrm{~h}$ (Figure 3c, fourth panel) also peak at low values, but this peak only reaches $12 \%$ and $9 \%$, respectively, as opposed to

Table 2. Percentage of Events That Have a Solar Wind Velocity $\mathrm{V}_{T}$ Greater Than 300, 350, 400, 450, 500, and $600 \mathrm{~km} / \mathrm{s}$

\begin{tabular}{lccccc}
\hline & $\begin{array}{c}\mathrm{V}_{T}> \\
350 \mathrm{~km} / \mathrm{s}\end{array}$ & $\begin{array}{c}\mathrm{V}_{T}> \\
400 \mathrm{~km} / \mathrm{s}\end{array}$ & $\begin{array}{c}\mathrm{V}_{T}> \\
450 \mathrm{~km} / \mathrm{s}\end{array}$ & $\begin{array}{c}\mathrm{V}_{T}> \\
500 \mathrm{~km} / \mathrm{s}\end{array}$ & $\begin{array}{c}\mathrm{V}_{T}> \\
600 \mathrm{~km} / \mathrm{s}\end{array}$ \\
\hline $\begin{array}{l}\text { Sawtooth } \\
\text { injections }\end{array}$ & $99 \%$ & $86 \%$ & $64 \%$ & $50 \%$ & $25 \%$ \\
$\begin{array}{l}\text { Isolated } \\
\text { substorms }\end{array}$ & $92 \%$ & $73 \%$ & $41 \%$ & $27 \%$ & $8 \%$ \\
$\begin{array}{l}\text { BRIs } \\
\begin{array}{l}\text { Background } \\
\text { data }\end{array}\end{array}$ & $65 \%$ & $21 \%$ & $6 \%$ & $1 \%$ & $0 \%$ \\
\hline
\end{tabular}


$29 \%$ for the sawtooth injections. Furthermore, the $\beta$ histogram does not drop off as sharply for the BRIs (Figures $3 b$ and $3 \mathrm{c}$, fourth panels) and the data also have a secondary peak near 0.4 . The solar wind $\beta$ for the substorms (Figure $3 \mathrm{~d}$, fourth panel) is statistically comparable to the background data with a $\chi^{2} \mathrm{p}$ value of 0.789 . The differences in the solar wind beta histograms indicate that it may play a role in determining which type of event occurs in the magnetosphere.

\subsection{Discussion of the Distributions}

[22] The solar wind/IMF drivers during the isolated substorms are very close to the background data, with the exception of $\mathrm{IMF} \mathrm{B}_{z}$ and $\mathrm{E}_{K \& L}$. The main reason for the differences in $\mathrm{B}_{z}$ and $\mathrm{E}_{K \& L}$ is that substorms almost always occur when the IMF $B_{z}$ is southward (negative). The background data are spread evenly over the IMF $B_{z}$, causing $\mathrm{E}_{K \& L}$ to peak at zero due to the $\theta$ term. Thus, with the exception of IMF $B_{z}$, the solar wind/IMF parameters for isolated substorms are virtually indistinguishable from the background data. This implies that the IMF $B_{z}$ is the most important component in the solar wind when determining if a substorm is likely to occur, thus supporting Caan et al. [1975, 1977] and McPherron et al. [1986].

[23] The data shown both during BRI events and the $2 \mathrm{~h}$ preceding them are very similar with some small differences. During the BRIs, and their preceding substorms $(2 \mathrm{~h}$ before the BRI) there is more deviation from the average of the solar wind/IMF drivers than during the isolated substorms. However, there are parameters that overlap with the background data, such as solar wind density and Alfven velocity. The IMF $\mathrm{B}_{z}$ (Figures $2 \mathrm{~b}$ and $2 \mathrm{c}$, first panels) and $\mathrm{E}_{K \& L}$ before and during the BRIs differ from the average data, but are similar to the isolated substorm data. This indicates that magnitude of IMF $\mathrm{B}_{z}, \mathrm{~V}_{A}, \mathrm{E}_{K \& L}$ and solar wind density may have little impact on the differences of magnetospheric dynamics during these two convection modes. Conversely, the solar wind temperature, total velocity, Alfvenic mach number, and plasma Beta differ from the average solar wind data and the substorm data. While the peak of the temperature histograms are the same value as the background data, the histograms have different shapes. Before and during BRIs, the temperature in the solar wind tends to be lower than average. Similarly, the solar wind velocity during this mode peaks close to the average data, but shifted slightly lower, and has a very small range $(\sim 300-450 \mathrm{~km} / \mathrm{s})$. Hence, there appears to be a very specific $\mathrm{V}_{T}$ in which BRIs occur. Since the Alfven velocity of the solar wind before and during BRIs is at values close to background data, the total velocity is the dominate term when calculating the Alfvenic mach number $\left(M_{A}=V_{T} / V_{A}\right)$. This causes a shift in the histograms to slightly lower values than the background data. Both during and for $2 \mathrm{~h}$ before BRI events, the $\beta$ is almost always lower than 1 , and usually less than 0.5. This means that the magnetic pressure is higher than the thermal pressure during these events. Since the IMF $\mathrm{B}_{z}$ and density during BRIs are similar to the values during substorms, it appears that the temperature is the differentiating factor when comparing $\beta$ for BRIs and substorms. This implies that the pressure ratio is due to a low thermal pressure and not necessarily a high magnetic pressure. In summary, BRIs and substorms are driven by similar IMF, but different solar wind conditions. Namely BRIs occur over a smaller range and at lower values of solar wind speed and at a lower plasma Beta.

[24] The individual sawtooth injections occur during the most extreme solar wind/IMF drivers of the three types of events studied here. The only parameter that has values that are insignificant when compared to the background data is the solar wind density. A sawtooth event is most likely associated with high solar wind speeds, strong negative IMF $\mathrm{B}_{z}$, and low temperatures, as observed during coronal mass ejections (CMEs) [Borovsky and Denton, 2006]. The Alfvenic Mach number $\left(\mathrm{V}_{T} / \mathrm{V}_{A}\right)$ is very low when compared to average solar wind data. Since the $\mathrm{V}_{T}$ is high, the low $\mathrm{M}_{A}$ is caused by the large $\mathrm{V}_{A}$. The solar wind plasma beta is also very low during these events. This is not unexpected after noting the low temperature, high IMF $\mathrm{B}$ and a nominal $n$, since $\beta=2 \mu_{o} n k T / B^{2}$. Thus, the solar wind magnetic pressure is much greater than the thermal pressure during the events. It has been noted recently that the magnetospheric interaction with the solar wind may be quite different under low Mach number and low $\beta$. For example, Lavraud et al. [2007] show that under nominal solar wind conditions, the $\nabla \mathrm{P}$ force is dominant in reaccelerating the solar wind in the magnetosheath, while during low $\beta$ cases, the $\mathrm{J} \times \mathrm{B}$ force is dominate since the magnetic field is dominate. Further, Ridley [2007] showed that during low Mach numbers, the magnetosphere has predominant Alfven wings, which may strongly influence the solar wind magnetosphere interaction. It has been shown that saturation of the ionospheric cross polar cap potential occurs under these conditions [Nagatsuma, 2002, 2004; Hairston et al., 2003; Ridley, 2005]. It is unknown whether any of these effects cause the magnetosphere to enter a sawtooth oscillation mode, but they are all present when sawteeth occur.

\section{Steadiness of Data}

\subsection{Histograms}

[25] It is not only the magnitude of the solar wind/IMF drivers that can effect the magnetosphere, but the changes in these drivers may also have an impact. Therefore, this portion of the investigation analyzes the steadiness of the drivers during individual sawtooth injections, BRIs, the $2 \mathrm{~h}$ before a BRI and isolated substorms. The steadiness of each parameter is defined as the standard deviation of the parameter during a 30 min interval divided by the mean for that interval. For each event, a running value of the steadiness is calculated for a $30 \mathrm{~min}$ period, and stepped by 5 min increments throughout the event. For example, if a substorm has an onset time of 02:00 UT, then the over all period used is 01:00 UT to 03:00 UT, the steadiness is calculated from 01:00 to 01:30, then from 01:05 to $01: 35$ and so on, with the last segment going from 02:30 to 03:00 UT. So, over the $2 \mathrm{~h}$ period there are 18 measurements of steadiness. The mean, peak, and standard deviation for each steadiness histogram are listed in Table 3 .

[26] It should be noted that when using one minute data to calculate the standard deviation high-frequency fluctuations will be averaged out. These high-frequency variations should not impact the convection mode the magnetosphere enters, thus we are more interested in larger-scale changes, such as a change in the direction of the IMF $\mathrm{B}_{z}$ or a pressure 
Table 3. Peak, Mean, and Standard Deviation for the Histograms in Figure 3

\begin{tabular}{|c|c|c|c|c|c|c|c|c|c|c|c|c|c|c|c|}
\hline & \multicolumn{3}{|c|}{$\begin{array}{c}\text { Sawtooth } \\
\text { Steadiness }\left(10^{-2}\right) \\
\end{array}$} & \multicolumn{3}{|c|}{$\begin{array}{c}\text { BRI/SMC } \\
\text { Steadiness }\left(10^{-2}\right) \\
\end{array}$} & \multicolumn{3}{|c|}{$\begin{array}{l}2 \mathrm{~h} \text { Before BRI/SMC } \\
\text { Steadiness }\left(10^{-2}\right)\end{array}$} & \multicolumn{3}{|c|}{$\begin{array}{c}\text { Substorm } \\
\text { Steadiness }\left(10^{-2}\right) \\
\end{array}$} & \multicolumn{3}{|c|}{$\begin{array}{c}\text { Background } \\
\text { Steadiness }\left(10^{-2}\right) \\
\end{array}$} \\
\hline & Mean & Peak & STD & Mean & Peak & STD & Mean & Peak & STD & Mean & Peak & STD & Mean & Peak & STD \\
\hline IMF $\left|B_{z}\right|$ & 47.38 & 0.30 & 95.49 & 29.03 & 5.47 & 44.55 & 39.43 & 5.78 & 56.30 & 61.32 & 10.97 & 76.07 & 65.75 & 10.24 & 74.36 \\
\hline SW Density & 13.31 & 6.18 & 10.20 & 8.52 & 5.27 & 6.31 & 8.55 & 5.04 & 5.40 & 8.21 & 4.90 & 6.26 & 8.18 & 4.64 & 6.17 \\
\hline SW Beta & 12.10 & 0.02 & 26.66 & 8.57 & 0.05 & 5.32 & 12.82 & 0.05 & 16.85 & 19.38 & 5.86 & 29.05 & 17.21 & 2.82 & 27.93 \\
\hline$\underline{\mathrm{E}}_{K \& L}$ & 16.70 & 0.23 & 21.84 & 11.40 & 3.61 & 11.34 & 15.69 & 3.59 & 14.88 & 22.21 & 3.60 & 18.42 & 21.89 & 6.00 & 18.47 \\
\hline
\end{tabular}

pulse. If a lower-resolution data set were used the standard deviation would be less and therefore our steadiness factor would be different. Since we are more interested in comparing the event types and not the value of the steadiness one minute data works well. It should also be noted that sudden changes in the drivers that may trigger substorm and sawtooth events may not show up predominantly in this study, since before and after the expansion phase onset there may be steady drivers. These changes in the drivers can be seen in the histograms but more steady data may appear to dominate the histogram. Thus, it is important not just to look at the peak but also the mean and the spread of the steadiness data.

[27] Figure 4 is composed of the steadiness of some solar wind/IMF parameters. Figures $4 \mathrm{a}-4 \mathrm{~d}$ (first panels) are histograms showing the absolute value of the steadiness of $\mathrm{B}_{z}$. Because the standard deviation is always positive, the calculated steadiness becomes positive (negative) when IMF $B_{z}$ is positive (negative). Since the IMF $B_{z}$ is predominately negative for all three event types, most of the steadiness data are negative, whereas the background data are about half positive and half negative. Thus, in order to truly compare the steadiness of the IMF $\mathrm{B}_{z}$ between the events and the background data, the absolute value of the steadiness is used in the histograms. The IMF $\mathrm{B}_{z}$ is steady during three out of the four convection modes. The variation in the IMF $\mathrm{B}_{z}$ for substorms (Figure $4 \mathrm{~d}$, first panel) is statistically the same as the background data since the $\chi^{2} \mathrm{p}$ value is 0.987 .

[28] The histograms in Figures 4a-4d (second panels) plot the steadiness of the solar wind density, which shows that during the interval around individual sawtooth injections (Figure 4a, second panel), the density in the solar wind is not as steady as during average times. However, the time before and during the BRIs (Figures $4 \mathrm{~b}$ and $4 \mathrm{c}$, second panels) and substorm intervals (Figure 4d, second panel) have large $\chi^{2} \mathrm{p}$ values and therefore have a solar wind density that is no more or less steady than during the background time.

[29] Figures $4 a-4 d$ (third panels and fourth panels) plot the steadiness of the solar wind beta and IMF $\mathrm{E}_{K \& L}$, respectively. They are similar to the steadiness of the IMF $\mathrm{B}_{z}$ only the isolated substorms (Figures $4 \mathrm{~d}$, third and fourth panels) have a steadiness that is comparable to the background data. The other convection modes are more steady than the background for beta and IMF $\mathrm{E}_{K \& L}$. This is most likely caused by the steadiness in the IMF $B_{z}$ for these events types.

\subsection{Discussion of Steadiness}

[30] During the isolated substorms used in this investigation, there appears to be no real difference between the steadiness of the solar wind/IMF drivers and the steadiness of the drivers during the background period. Thus, many of these substorm expansions may be triggered by an internal magnetospheric process or an external trigger that is too rapid to be detected using this methodology.

[31] Both before and during BRI events the IMF $\mathrm{B}_{z}$ is very steady. The steadiness in $\mathrm{B}_{z}$ also creates a steadiness in the solar wind plasma $\beta$ and the $\mathrm{E}_{K \& L}$. The other data shown are comparable to the steadiness of the background intervals. This strongly supports the theory that a steady IMF $\mathrm{B}_{z}$ is an important component of the driving during BRI events [Sergeev et al., 1994].

[32] The time intervals studied for the individual sawtooth injections, $1 \mathrm{~h}$ before to $1 \mathrm{~h}$ after, show that the IMF $\mathrm{B}_{z}$ is very steady during this time, possibly even more steady than during BRIs. However, unlike the BRIs, the density is not very steady during these intervals. The less steady nature of the density implies that some of the sawtooth injections presented here could have been pressure triggered. A superposed epoch of the data would elucidate this statement, but is beyond the scope of this paper.

[33] It appears that BRIs and sawtooth oscillations both occur when the IMF $\mathrm{B}_{z}$ driver is steady, creating a steady $\mathrm{E}_{K \& L}$ and $\beta$, but the changes in solar wind density may be a factor in why the magnetosphere enters a sawtooth mode instead of a BRI mode. Exactly how steady or unsteady the IMF $\mathrm{B}_{z}$ and solar wind density need to be to create these different convection modes is unknown and requires further investigation.

\section{Discussion}

\subsection{Solar Wind/IMF Drivers}

[34] This investigation shows that there are different drivers, both in size and steadiness, for individual sawtooth injections, BRIs, and isolated substorms. The IMF $\mathrm{B}_{z}$ is comparable in magnitude for the BRIs and isolated substorms, and comparable in steadiness for the BRIs and individual sawteeth. Thus, if the IMF $\mathrm{B}_{z}$ is moderate $(\sim-4 \mathrm{nT})$ and not very steady, then a substorm is most likely to occur. If $\mathrm{B}_{z}$ is moderate and steady, then an BRI is most likely to occur. Finally, if it is strong $(<-10 \mathrm{nT})$ and steady, a sawtooth oscillation is most probable. Because most of the histograms for the substorms are very similar to the 6 years of background data, it appears that the IMF $\mathrm{B}_{z}$, and therefore $\mathrm{E}_{K \& L}$, is the most important driver during isolated substorms. Please note that this investigation is only for isolated substorms that can be measured by midlatitude magnetometers, thus small high-latitude and storm time substorms have not been included.

[35] Since fifty out of fifty-one BRI events have a substorm in the $2 \mathrm{~h}$ preceding them, the data plotted in Figures $2 \mathrm{c}, 3 \mathrm{c}$, and $4 \mathrm{c}$ can be considered the initiating substorms of BRIs. Thus, it is interesting to note that their histograms both in 
the data and in the steadiness are more similar to BRIs (Figures 2b, 3b, and $4 \mathrm{~b}$ ) than isolated substorms (Figures $2 \mathrm{~d}$, $3 \mathrm{~d}$, and $4 \mathrm{~d})$. This indicates that initiating substorms of BRIs have different drivers than the isolated substorms investigated here. Thus, the solar wind conditions may be a factor in preconditioning the magnetosphere to allow a BRI to occur. During the initiating substorms for BRIs the IMF $B_{z}$ is almost as steady as it is during the BRI itself, as opposed to the isolated substorms that had IMF $B_{z}$ steadiness that is similar to the background data. This indicates that initiating substorms are most likely NOT triggered by a change in the IMF $\mathrm{B}_{z}$; however, IMF $\mathrm{B}_{y}$ is not investigated and could be a triggering mechanism.

[36] Hsu and McPherron [2003] state that 60 percent of substorms are triggered by a northward turning in IMF $\mathrm{B}_{z}$. Yet, these initiating substorms seem to strongly favor no triggering. Hence, is there a relationship between untriggered substorms and BRIs (SMCs)? Along with the solar wind drivers initiating substorms may be an important factor in preconditioning the magnetosphere in order to allow reconnection rates to balance. When the IMF $B_{z}$ is steady for an extended period of time, it appears that the tail will load with magnetic flux then release the flux before it can achieve a steady state, as opposed transitioning into a steady state right away. This supports the idea that tail configuration during BRIs (SMCs) is in between recovery phase and growth phase configurations [Sergeev et al., 1996]. However, a substorm is not necessary for preconditioning for BRIs since 1 of the 50 events does not begin with a substorm [DeJong et al., 2008]. In order to fully investigate the role of initiating substorms on the balance of reconnection rates, a superposed epoch analysis, using the onset time of the initiating substorm, of IMF $\mathrm{B}_{z}$ and other parameters will need to be studied. Also a better comparison of initiating substorms to isolated substorms is called for. It is the intention of the authors to continue this work with just such a study.

[37] The magnitude of the solar wind velocity and temperature, and their effects on the solar wind Beta, Alfvenic Mach number and $\mathrm{E}_{K \& L}$, appear to play a role in the driving of BRIs and sawtooth oscillations. Both the solar wind Beta and Mach numbers $\left(\mathrm{M}_{A}\right.$ and $\left.\mathrm{M}_{M S}\right)$ are lower than average for both the BRI and sawtooth intervals, where the later events deviate to the lower end of the spectrum. The $\mathrm{M}_{A}$ for the sawtooth events appears to be caused by the large $\mathrm{V}_{A}$, which is dominated by the large magnitude of the IMF $\mathrm{B}_{z}$. The BRI $\mathrm{M}_{A}$ seems to be influenced mostly by the low $\mathrm{V}_{T}$. Lopez et al. [2004] state that when the $\mathrm{M}_{A}$ is small, the compression ratio of the bow shock is low, causing less solar wind kinetic energy to be converted to magnetic energy in the magnetosheath. However, if the density during this time is high, then the compression ratio increases along with the energy conversion. Thus, both the magnitude and steadiness of the solar wind density most likely play a larger role in the driving of sawtooth oscillations. The histograms show that the density is nominal in magnitude but less steady during sawtooth injections which supports the idea that some of the individual teeth may be triggered by pressure changes in the solar wind [Huang et al., 2005; Lopez et al., 2004].

[38] The solar wind temperature during sawtooth injections is low the majority of the time, but can reach higher temperatures. This, along with the low $\mathrm{M}_{M S}$, supports the idea that global sawtooth oscillations are most likely to occur during CMEs [Borovsky and Denton, 2006]. Whether or not they occur because of the low temperatures and Mach numbers, or if the data are biased this way because they mostly occur during CMEs, is not yet known.

\subsection{Solar Wind Velocity and Its Implications on Balanced Reconnection Rates}

[39] BRIs are highly unlikely to occur when the solar wind is fast. Conversely, the solar wind velocity for the sawtooth intervals appears to be bimodal and is larger than the background data. Table 3 lists the percentage of events that have a $\mathrm{V}_{T}$ larger than a given velocity. It is interesting to note that $50 \%$ of the time the solar wind velocity is greater than $500 \mathrm{~km} / \mathrm{s}$ during sawteeth, while only $1 \%$ of the BRIs data points are greater than $500 \mathrm{~km} / \mathrm{s}$. These low solar wind velocities during BRIs (SMCs) agree with $O$ 'Brien et al. [2002], who found that most SMCs (BRIs) happen when the solar wind velocity is below $450 \mathrm{~km} / \mathrm{s}$. Also $35 \%$ of the $\mathrm{V}_{T}$ data points during BRIs are less than $350 \mathrm{~km} / \mathrm{s}$, while very few isolated substorms or sawteeth occur at this slow of a speed.

[40] Due to a similar steadiness in the IMF $B_{z}$ during both BRIs and individual sawtooth injections, it appears that the solar wind velocity may play a role in whether or not dayside and nightside reconnection rates will balance. To investigate this further we must first look at how the amount of open magnetic flux in the polar cap relates to reconnection rates. Siscoe and Huang [1985] state the following formulation of Faraday's Law:

$$
\frac{d F_{p c}(t)}{d t}=\Phi_{D}(t)-\Phi_{N}(t)
$$

where $\mathrm{F}_{p c}$ is the amount of open flux in the polar cap, and $\Phi_{D}$ and $\Phi_{N}$ are the dayside and nightside reconnection rates, respectively. Hence, the temporal evolution of the $\mathrm{F}_{p c}$ can indicate a balance or imbalance of reconnection rates [Siscoe and Huang, 1985; Cowley and Lockwood, 1992]. During BRIs, the dayside and nightside reconnection rates are balanced [Sergeev et al., 1996] and the polar cap flux is constant [DeJong et al., 2007]. The $\mathrm{F}_{p c}$ for the individual sawteeth becomes larger before the injection and loses about $30 \%$ of its open flux after the injection, indicating that the dayside reconnection rate is larger before the injection, and the nightside reconnection rate is larger after the injection, similar to a substorm.

[41] If the formulation for the dayside reconnection rate is [Holzer et al., 1986; Milan et al., 2006]:

$$
\Phi_{D}= \begin{cases}L_{e f f} V_{s w} B_{z}, & B_{z}<0 \\ 0, & B_{z}>0\end{cases}
$$

where $L_{e f f}$ is the effective length of the equatorial reconnection line. If it is assumed that $L_{\text {eff }}$ remains constant during the reconnection event [Milan et al., 2007] and that $E_{y} \simeq V_{s w} B_{z} \simeq E_{K \& L}$, then for both individual sawteeth and BRIs it can be stated that $\Phi_{D}$ remains steady. This indicates that the solar wind velocity plays a large role in the balance of reconnection rates. An example of an event where this occurs is the February 17, 1998 BRI event. During the $5 \mathrm{~h}$ 
event the $\mathrm{V}_{x}$ averages $-394 \pm 5.8 \mathrm{~km} / \mathrm{s}$ and the $\mathrm{IMF} \mathrm{B}_{z}$ is $-8.24 \pm 1.15 \mathrm{nT}$. While the $\mathrm{V}_{x}$ is close to other BRI velocities, the IMF $B_{z}$ is more of what is expected for sawtooth injections. So, the magnetosphere enters an BRI mode instead of a sawtooth mode, most likely due to the lower $\mathrm{V}_{x}$. This event and the statistical data presented here support the idea that if $\Phi_{D}$ is steady and the solar wind velocity is low ( $\leq \sim 450 \mathrm{~km} / \mathrm{s})$, then the magnetosphere can reach a steady state. If the solar wind velocity is large, then internal processes in the magnetosphere do not allow the reconnection rates to balance, periodically loading and unloading the tail. What exactly these internal magnetospheric processes are and how they are controlled by the solar wind velocity is as yet unknown.

[42] Others have also studied the importance of the solar wind velocity on the steadiness of the magnetosphere. Using the Lyon-Fedder-Mobary (LFM) model, Pulkkinen et al. [2007a] found that the driving of the magnetosphere is not only dependent on the driving electric field but also depends on its constituents. They state that, under relatively steady driving conditions, higher solar wind speeds lead to a more dynamic magnetosphere. Our statistical data support these statements, in that the steadiness of our $\mathrm{B}_{z}$ is comparable for the sawteeth and substorms, yet the solar wind speed is much larger for sawtooth injections. It also appears that if the solar wind speed becomes too large, then the magnetosphere cannot stay stable and steady magnetospheric convection will not occur.

\section{Conclusion}

[43] The magnetosphere enters a BRI mode only under very particular solar wind drivers. The ranges on the data for these events are much lower than during either isolated substorms or individual sawteeth. Thus, it appears that when the dayside reconnection rate is stable, the nightside reconnection rate is more likely to be able to match it when the solar wind is below $\sim 450 \mathrm{~km} / \mathrm{s}$. This indicates that there is an internal mechanism in the magnetosphere that will allow for this balance only when the velocity is low. Whether it is the velocity, $\mathrm{E}_{K \& L}$ or the magnitude of the dayside reconnection that is the most important is unknown at this time and needs further investigation.

[44] Unlike BRIs, sawtooth oscillations can occur over a wide range of drivers and activity levels. The most predominate drivers appear to be a strong steady IMF $\mathrm{B}_{Z}$, low solar wind temperature, high solar wind $\mathrm{V}_{T}$, and low solar wind Mach numbers. All of these parameters are found during coronal mass ejections (CMEs). It may be difficult therefore to determine which drivers are most important and which drivers are unimportant.

[45] The substorms that initiate BRIs along with their solar wind and IMF drivers appear to play an important role in determining if reconnection rates can balance. Thus, these initiating substorms are different from the isolated substorms studied here and should be categorized separately, just as we have separated isolated substorms from sawtooth injections and storm time periodic substorms. The exact role of these initiating substorms and how they differ from other substorms needs to be investigated in much more detail.
[46] The situation of driving these different types of events is not as simple as, moderate driving creates a substorm, moderate steady driving creates an BRI and strong steady driving creates a global sawtooth oscillation. It appears that the magnitude of the solar wind velocity along with magnitude and steadiness of the IMF $\mathrm{B}_{z}$ are the most import factors in determining what type of mode the magnetosphere will enter. However, other drivers, such as steadiness of the solar wind density and magnitude of the Mach numbers could also play a role in sawtooth oscillations.

[47] Acknowledgments. The authors would like to thank James Weygand for the propagated solar wind and IMF data. This work was supported in part at the University of Michigan by grants from NSF (grant ATM0639336) and AFOSR (grant FA9550). Support for Virginia Tech was supplied by NASA grant NNX07AH23G (NASA guest investigator) and NSF ATM-0725094. The author also gratefully acknowledges NASA GSRP support through grant NNM04AA05H, under which most of the research was performed. Finally, the authors would like to acknowledge the GEM workshops sponsored by NSF.

[48] Zuyin Pu thanks the reviewers for their assistance in evaluating this paper.

\section{References}

Borovsky, J. E., and M. H. Denton (2006), Differences between CMEdriven storms and CIR-driven storms, J. Geophys. Res., 111, A07S08, doi:10.1029/2005JA011447.

Caan, M. N., R. L. McPherron, and C. T. Russell (1975), Substorm and interplanetary magnetic field effects on the geomagnetic tail lobes, J. Geophys. Res., 80, 191-194.

Caan, M. N., R. L. McPherron, and C. T. Russell (1977), Characteristics of the association between the interplanetary magnetic field and substorms, J. Geophys. Res., 82, 4837-4842.

Cai, X., C. Clauer, and A. Ridley (2006a), Statistical analysis of ionospheric potential patterns for isolated substorms and sawtooth events, Ann. Geophys., 24, 1977-1991.

Cai, X., M. Henderson, and C. Clauer (2006b), A statistical study of magnetic dipolarization for sawtooth events and isolated substorms at geosynchronous orbit with goes data, Ann. Geophys., 24, 3481-3490.

Chernoff, H., and E. L. Lehmann (1954), The use of maximum likelihood estimates in $\chi^{2}$ test for goodness of fit, Ann. Math. Stat., 25, 579-586.

Clauer, C. R., X. Cai, D. Welling, A. DeJong, and M. G. Henderson (2006), Characterizing the 18 April 2002 storm-time sawtooth events using ground magnetic data, J. Geophys. Res., 111, A04S90, doi:10.1029/ 2005JA011099.

Cowley, S., and M. Lockwood (1992), Excitation and decay of solar winddriven flow in the magnetophere-ionosphere system, Ann. Geophys., 10, $103-115$.

DeJong, A. D., and C. R. Clauer (2005), Polar UVI images to study steady magnetospheric convection events: Initial results, Geophys. Res. Lett., 32, L24101, doi:10.1029/2005GL024498.

DeJong, A. D., X. Cai, C. R. Clauer, and J. F. Spann (2007), Aurora and open magnetic flux during isolated substorms, sawteeth, and SMC events, Ann. Geophys., 25, 1865-1876.

DeJong, A. D., A. J. Ridley, and C. R. Clauer (2008), Balanced reconnection intervals: Four case studies, Ann. Geophys., 26, 3897-3912.

Hairston, M. R., T. W. Hill, and R. A. Heelis (2003), Observed saturation of the ionospheric polar cap potential during the 31 March 2001 storm, Geophys. Res. Lett., 30(6), 1325, doi:10.1029/2002GL015894.

Henderson, M. G. (2004), The May 2-3, 1986 CDAW-9C interval: A sawtooth event, Geophys. Res. Lett., 31, L11804, doi:10.1029/ 2004 GL019941.

Henderson, M. G., G. D. Reeves, R. Skoug, M. F. Thomsen, M. H. Denton, S. B. Mende, T. J. Immel, P. C. Brandt, and H. J. Singer (2006a), Magnetospheric and auroral activity during the 18 April 2002 sawtooth event, J. Geophys. Res., 111, A01S90, doi:10.1029/2005JA011111.

Henderson, M. G., et al. (2006b), Substorms during the 10-11 August 2000 sawtooth event, J. Geophys. Res., 111, A06206, doi:10.1029/ 2005JA011366.

Holzer, R. E., R. L. McPherron, and D. A. Hardy (1986), A quantitative empirical model of the magnetospheric flux transfer process, J. Geophys. Res., 91, 3287-3293

Hones, E. W., Jr., T. Pytte, and H. I. West Jr. (1984), Associations of geomagnetic activity with plasma sheet thinning and expansion: A statistical study, J. Geophys. Res., 89, 5471-5478. 
Hsu, T.-S., and R. L. McPherron (2003), Occurrence frequencies of IMF triggered and nontriggered substorms, J. Geophys. Res., 108(A7), 1307, doi:10.1029/2002JA009442.

Huang, C.-S., G. D. Reeves, J. E. Borovsky, R. M. Skoug, Z. Y. Pu, and G. Le (2003), Periodic magnetospheric substorms and their relationship with solar wind variations, J. Geophys. Res., 108(A6), 1255, doi:10.1029/ 2002JA009704

Huang, C.-S., G. D. Reeves, G. Le, and K. Yumoto (2005), Are sawtooth oscillations of energetic plasma particle fluxes caused by periodic substorms or driven by solar wind pressure enhancements?, J. Geophys. Res., 110, A07207, doi:10.1029/2005JA011018.

Kan, J. R., and L. C. Lee (1979), Energy coupling function and solar windmagnetosphere dynamo, Geophys. Res. Let., 6, 577-580.

Lavraud, B., J. E. Borovsky, A. J. Ridley, E. W. Pogue, M. F. Thomsen, H. Rème, A. N. Fazakerley, and E. A. Lucek (2007), Strong bulk plasma acceleration in Earth's magnetosheath: A magnetic slingshot effect?, Geophys. Res. Lett., 34, L14102, doi:10.1029/2007GL030024.

Lopez, R. E., M. Wiltberger, S. Hernandez, and J. G. Lyon (2004), Solar wind density control of energy transfer to the magnetosphere, Geophys. Res. Lett., 31, L08804, doi:10.1029/2003GL018780.

McPherron, R. L., T. Teresawa, and A. Nishida (1986), Solar wind triggering of substorm expansion onset, J. Geomagn. Geoelectr., 38, $1089-$ 1108 .

McPherron, R. L., J. M. Weygand, and T.-S. Hsu (2008), Response of the Earth's magnetosphere to changes in the solar wind, J. Atmos. Terr. Phys. 70, 303-315

Milan, S., J. Wild, A. Grocott, and N. Draper (2006), Space- and groundbased investigations of solar wind-magntosphere-ionosphere coupling, Adv. Space Res., 38, 1671-1677.

Milan, S. E., G. Provan, and B. Hubert (2007), Magnetic flux transport in the Dungey cycle: A survey of dayside and nightside reconnection rates, J. Geophys. Res., 112, A01209, doi:10.1029/2006JA011642.

Nagatsuma, T. (2002), Saturation of polar cap potential by intense solar wind electric fields, Geophys. Res. Lett., 29(10), 1422, doi:10.1029/ 2001 GL014202.

Nagatsuma, T. (2004), Conductivity dependence of cross-polar potential saturation, J. Geophys. Res., 109, A04210, doi:10.1029/2003JA010286.

O'Brien, T. P., S. M. Thompson, and R. L. McPherron (2002), Steady magnetospheric convection: Statistical signatures in the solar wind and AE, Geophys. Res. Lett., 29(7), 1130, doi:10.1029/2001GL014641.

Pulkkinen, T. I., C. C. Goodrich, and J. G. Lyon (2007a), Solar wind electric field driving of magnetospheric activity: Is it velocity or magnetic field?, Geophys. Res. Lett., 34, L21101, doi:10.1029/2007GL031011.
Pulkkinen, T. I., N. Partamies, R. L. McPherron, M. Henderson, G. D. Reeves, M. F. Thomsen, and H. J. Singer (2007b), Comparative statistical analysis of storm time activations and sawtooth events, J. Geophys. Res., 112, A01205, doi:10.1029/2006JA012024.

Reeves, G. D., M. F. Thomsen, M. G. Henderson, R. M. Skoug, J. E. Borovsky, J.-M. Jahn, C. J. Pollock, D. G. Brandt, and S. B. Mende (2002), Global "sawtooth" activity in the April 2002 geomagnetic storm, Eos Trans. $A G U, 83(47)$, Fall Meet. Suppl., Abstract SA12A-05.

Ridley, A. J. (2005), A new formulation for the ionospheric cross polar cap potential including saturation effects, Ann. Geophys., 23, 3533-3547.

Ridley, A. J. (2007), Alfvén wings at Earth's magnetosphere under strong interplanetary magnetic fields, Ann. Geophys., 25, 533-542.

Russell, C. T., and R. L. McPherron (1973), The magnetotail and substorms, Space Science Reviews, 15, 205-266.

Sergeev, V. A., T. I. Pulkkinen, T. I. Pellinen, and N. A. Tsyganenko (1994), Hybird state of the tail mangetic configuration during steady convection events, J. Geophys. Res., 99, 23,571-23,582.

Sergeev, V., R. Pellinen, and T. Pulkkinen (1996), Steady magnetospheric convection: A review of recent results, Space Sci. Rev., 75, 551-604.

Siscoe, G., and T. Huang (1985), Polar cap inflation and deflation, J. Geophys. Rev. 90, 543-547.

Weimer, D. R. (2004), Correction to "Predicting interplanetary magnetic field (IMF) propagation delay times using the minimum variance technique," J. Geophys. Res., 109, A12104, doi:10.1029/2004JA010691.

Weimer, D. R., D. M. Ober, N. C. Maynard, W. J. Burke, M. R. Collier, D. J. McComas, N. F. Ness, and C. W. Smith (2002), Variable time delays in the propagation of the interplanetary magnetic field, J. Geophys. Res., 107(A8), 1210, doi:10.1029/2001JA009102.

Weimer, D. R., D. M. Ober, N. C. Maynard, M. R. Collier, D. J. McComas, N. F. Ness, C. W. Smith, and J. Watermann (2003), Predicting interplanetary magnetic field (IMF) propagation delay times using the minimum variance technique, J. Geophys. Res., 108(A1), 1026, doi:10.1029/ 2002JA009405.

X. Cai and C. R. Clauer, Bradley Department of Electrical and Computer Engineering, Virginia Polytechnic Institute and State University, 302 Whittemore Hall, Blacksburg, VA 24061, USA.

A. D. DeJong, Southwest Research Institute, P.O. Drawer 28510, San Antonio, TX 78229, USA. (adejong@swri.edu)

A. J. Ridley, Department of Atmospheric, Oceanic, and Space Sciences, University of Michigan, Ann Arbor, MI 48109, USA. 